\title{
Tackling the Big Challenges of the Future
}

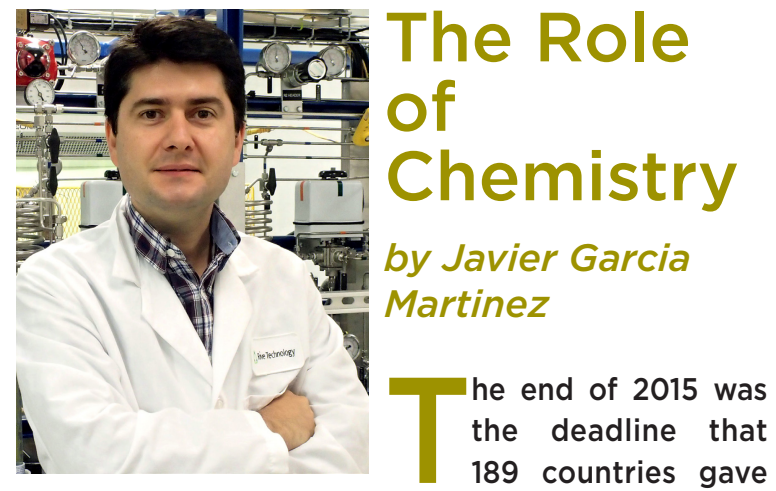

themselves to achieve the United Nations Millennium Development Goals (MDGs), a list of eight goals that were agreed upon and approved by the UN after the Millennium Summit in year 2000. Despite some legitimate criticism, the MDGs were revealed as an important tool towards building a more equitable and sustainable world. Yet our planet still faces many challenges. In September 2015, the UN approved a new set of 17 goals, the Sustainable Development Goals (SDGs), aiming to develop and implement strategies to create "The Future We Want"; strategies that 192 countries agreed upon to work together towards a more sustainable planet [1].

The price to pay for inaction is too high. Climate change, water scarcity, pollution, and energy poverty are just a few examples of the big problems that we face today. Chemistry has a central role to play in tackling these and many other coming challenges. Indeed, for decades chemists have provided countless solutions that have greatly contributed to the health, well-being, and development of humankind, from the discovery of new medicines to the purification of water. Still, it is important to emphasize that these discoveries have not always improved people's lives. Scientific developments are sometimes misused. A striking example is the fixation of nitrogen through the Haber-Bosch process, which allows for the production of food for half of the world's population [2]. Yet the same process was used during World War I in the production of weapons. Chemists have a particular responsibility to meet the needs of a planet of 7 billion people without compromising the well-being of future generations and without misusing technology with the purpose of destruction.

Realizing certain SDGs will not only require better technology but also the political willingness to act. For example, there is no acceptable reason why over a billion people have no access to safe drinking water, or that 2.6 billion people lack adequate sanitation. These factors explain why 1.8 million people die every year

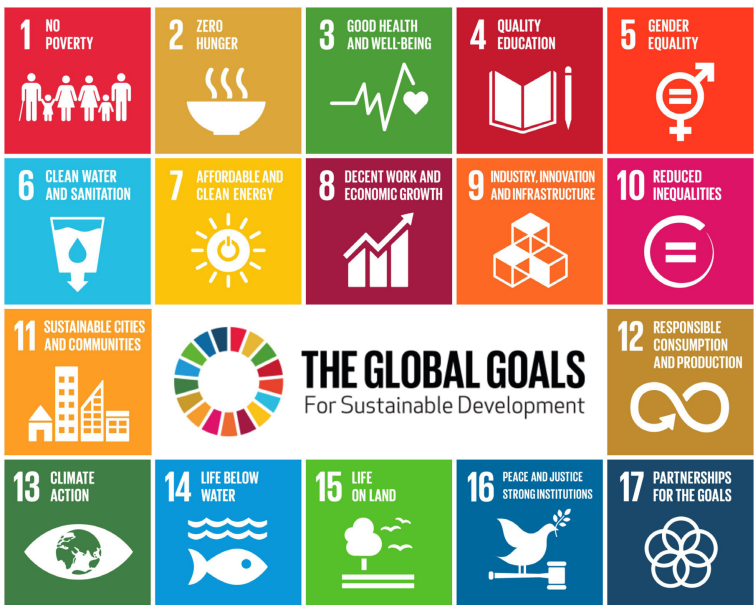

from diarrheal diseases and $90 \%$ of the victims are children under 5 years of age. Indeed, plenty of already available technologies can make a difference in the lives of millions of people, such as mosquito nets, more robust and nutritious crops, and decentralized energy systems. The benefits of making these technologies available around the world would have an overwhelming effect, as pointed out by many experts [3].

On the other hand, some challenges described in the SDGs depend on the availability of better, more effective materials, more efficient drugs, and cleaner alternative energy systems. Here, science in general, and chemistry in particular, is critically needed to create the solutions to the huge technical challenges behind each of these goals. [4] However, in many ways there is a misalignment between the SDGs and the goals of many scientists, granting programs, and major research and academic institutions. A new generation of chemists is needed to achieve these goals, one trained with a bias toward the needs of our planet and supported by national and international research funding calls that address these Goals. Here, IUPAC and other international organizations can be key players in aligning the incentives and the priorities of the global R\&D agenda.

The chemical industry, motivated by increasingly demanding regulations, is making significant progress towards more environmentally friendly processes, from reductions in the use of solvents, to the adoption of highly efficient catalysts. The commitment of chemical industries to the principles of green chemistry is clear, but these principles must be universally applied, especially in those countries where regulations are not as strict. Green chemistry and circular economy make sense, not only from the environmental point of view, but also from the business side. The "circular economy" advocates for the reuse and service-life extension of goods as a strategy of waste prevention analysis based 
on the full cycle analysis of every product, as opposed to the current, linear, "take, make, dispose" model. These concepts are of great importance for the education of chemistry students, who are currently rarely exposed to them.

There are many exciting new inventions and discoveries that help us see a brighter future. Artificial photosynthesis, for example, is one of special interest. For the first time, we are about to be able to produce different carbohydrates directly from $\mathrm{CO}_{2}$ and water using merely sunlight. It is already possible to split water using an artificial leaf: a wireless, low-cost, thin film amorphous silicon multi-junction cell that, when immersed in water, directly produces hydrogen and oxygen. Though these new developments are very distant from commercialization, it is advances like them that will shape future energy production.

Despite the many benefits of the Haber-Bosch process, technologies for nitrogen fixation that are less energy intensive and that avoid very high $\mathrm{H}_{2}$ pressure would be highly desirable. Advances in bio-organometallics and materials chemistry are greatly increasing the efficiency of biomimetic analogs of nitrogenase, a natural enzyme that fixes atmospheric nitrogen at room temperature and pressure without the need of molecular hydrogen.

Recent reports show how Earth-abundant elements, such as iron, cobalt, and nickel, are excellent alternatives to scarce metals like platinum, rhodium, and gold for catalysis. These results show that it is both possible and highly desirable to move away from scarce minerals, especially those from areas of the world that are in conflict, to Earth-abundant materials. A good example is the use of layered iron and nickel nanomaterial as a more sustainable alternative to rare-earth "supermagnets".

Key to several SDGs is to keep global temperature rise to a minimum level. The solutions proposed by chemists have so far focused mainly on capturing and sequestering $\mathrm{CO}_{2}$. But new insights are emerging from quite promising research on the use of $\mathrm{CO}_{2}$ as a feedstock for the production of various useful chemicals. The main objective and challenge here is to do so without producing even more $\mathrm{CO}_{2}$, i.e., using energy produced from fossil fuels. An interesting possibility is to convert $\mathrm{CO}_{2}$ into methane using light and amine-functionalized titanium dioxide nanoparticles, a system that has been recently developed by scientists in Singapore.

These are just a few examples of the opportunities

namely the Division on Chemistry and the Environment (Div VI), the Committee on Chemistry Education (CCE), and the Committee on Chemistry and Industry ( $\mathrm{COCl})$. The theme selected for the 2015 WCLM was: IUPAC's Role in Achieving United Nations Sustainable Development Goals. This theme also builds on the ideas developed for IUPAC's newly launched strategic plan (see Chem Int. 38(1), Jan-Feb 2016, pp. 4-5). The

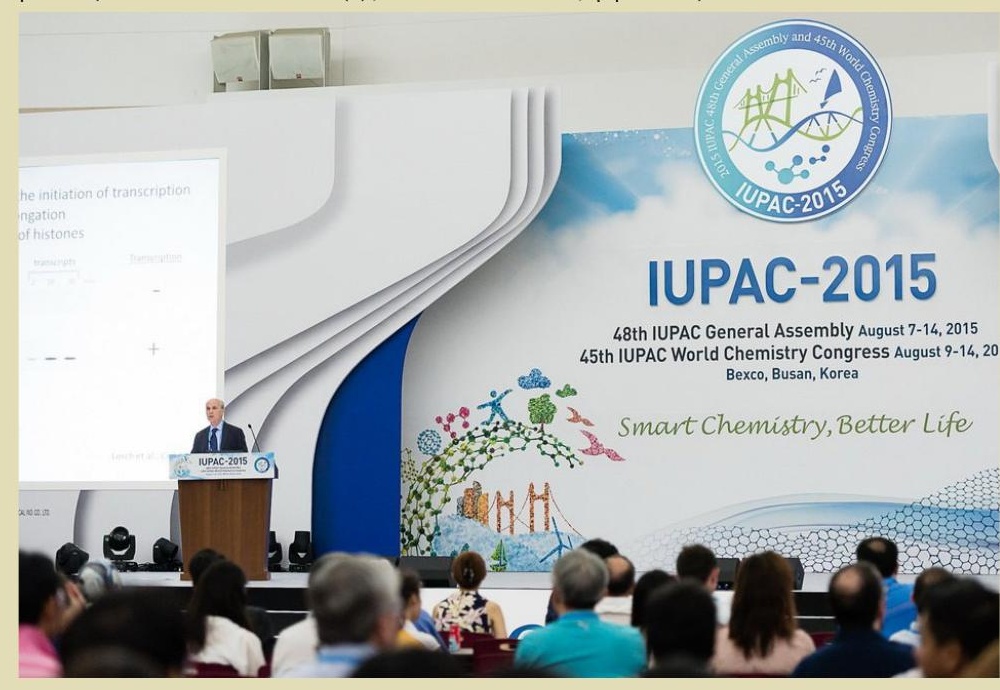




\section{Tackling the Big Challenges of the Future}

that chemistry offers, but many more discoveries are needed. To make them possible, a new generation of chemists committed to tackle these big challenges is required. One should wonder, then, if we are educating our students to solve real problems and providing them with the knowledge and skills needed to do so. The introduction and development of new areas of chemistry, such as chemical biology, nanotechnology, or bioinorganics, have blurred the lines between the traditional branches of chemistry. These divisions are not only artificial, but in many ways they are counterproductive, not only from the educational point of view, but also for the advancement of chemistry. Even the borders of chemistry are falling, especially as biochemistry, materials science, and nanotechnology are rapidly growing. However, text books, college courses, and many chemistry departments are structured around rigidly defined subdisciplines. Everyone agrees that change towards interdisciplinarity is needed, but little is being done to teach, communicate, and do research in a more holistic and inclusive way, in a manner that will be most useful for the chemistry of the 21st century, and with the aim to establish truly curiosity-driven science. Recently, Peter Atkins and I had the privilege to publish an article in this newsmagazine on how chemistry can be communicated and learned more effectively, on the occasion of

pressures of population growth and worldwide climate change, as well as the opportunities offered by the development of a new era of global interaction, have led to an understanding of the need to redefine the role of the scientific and industrial professional communities in addressing sustainable development and offering suitable solutions relevant to all walks of life.

The primary objectives of the WCLM were to: 1)

Professor Yuan Tseh Lee discussing the education of girls in developing countries and population explosion at the 2015 WCLM.

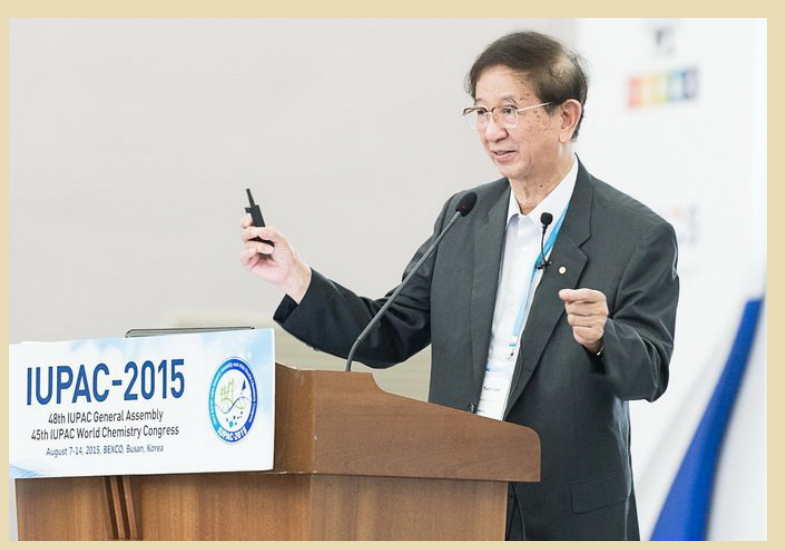

the publication of a new book on Chemistry Education, in which some challenges and opportunities are critically discussed [5].

But exciting new research is not enough to tackle the really big challenges. It is also urgent to bring these breakthroughs from the lab to the marketplace. Chemistry entrepreneurs are among the most powerful and transformative agents in the building of a brighter, more sustainable future. A few months ago, during a special symposium that the American Chemical Society organized on the topic of Chemistry Entrepreneurship, "International Entrepreneurship: How to Start a Business and Thrive in Global Marketplace," I had the opportunity to share some first-hand experiences on how to commercialize chemistry discoveries coming from the lab. During that meeting, it became clear that there are plenty of opportunities to commercialize exciting new technologies that have been discovered in universities and research labs. Chemistry entrepreneurs bring technologies from the lab to the marketplace, shortening the time from discovery to the point where everybody can benefit from them. They help to create value and jobs, and diversify the economy. Some of the most successful and highly cited chemists, such as George Whitesides, Bob Langer, and Paul Workman, are also the founders of numerous companies. If we engage YOs and ask them for their ideas on the best way that IUPAC can contribute to accomplishing the UN Sustainable Development Goals, 2) develop a program of distinguished invited speakers to present their ideas on the UN SDGs and to hear ideas developed by groups of YOs, and 3) ultimately create an IUPAC-UNSDG working group to facilitate the development and implementation of projects based on the outcomes of the WCLM.

The WCLM project team worked to compile background materials from the UN and recent opinion pieces in the peer-reviewed literature on the SDGs [1] and provided these to approximately 35 YOs from 12 countries in advance of the Busan meeting. A reception was held on the evening of Monday 10 August to brief YOs on WCLM activities. On Tuesday 11 August, the YO forum was held to facilitate the exchange of ideas in discussion groups. These groups discussed the gaps in existing knowledge and practice and the ways these can be addressed through defined projects and project proposals. Five groups worked on these project proposals over the course of two days.

The proposals attempt to address dissemination and education capacity in the chemical and general 
want to develop the ambitious solutions we need for the SDGs in the next decade, we need not only new breakthroughs, but also those who can better translate them into a commercial reality. Academic entrepreneurs are bridges that close the gap between industry and academia, discovery and solution. [6]

An opinion article that appeared in Nature mentioned that, "Addressing climate change, renewable energy, food, health and water provision requires coordinated global monitoring and modeling of many factors-social, economic, and environmental". [7] This is a major task that will be possibly only through a global multi-stakeholder approach of unprecedented scale, including governments, natural scientists, social scientists, engineers, industry, and civil society.

ICSU has prepared a report in which the 17 Sustainable Development Goals and 169 targets are critically reviewed, as submitted to the UN General Assembly by the UN Open Working Group (OWG). [8] The role of science is widely accepted to be critically important in identifying, monitoring, and achieving the Global Goals [9]. However, as ICSU clearly states in its report, the collaboration between policy makers, the scientific community, and other stakeholders is critically important, and requires careful attention.

In August 2015, a few weeks ahead of the official

communities, or to produce scientific guidelines and assessments on specific topics. The proposals developed are:

1. Increasing Awareness of IUPAC Project Impacts and Resources

2. Water Narratives: Providing Resources for Cleaner Water for All

3. Water4life-Global map of water quality and technologies

4. Guidelines for Sustainable Catalysis and their Implementation

5. Assessment of the Status of Phosphate Recycling.

These proposal topics were presented by the YOs on Wednesday 12 August to the assembled IUPAC community audience in an exciting plenary session which also included presentations by eminent scientists and professionals in the sphere of chemistry. Professor Yuan-Tseh Lee, Nobel Laureate, from the Institute of Atomic and Molecular Sciences in Taiwan, discussed the 'Education of Girls in Developing Countries and Population Explosion'. Dr. Hubert Mandery, Director General of the European Chemical Industry Council (Cefic) referred to concerns about 'Resource Consumption and approval of the SDGs, chemists from all around the world gathered in Busan, South Korea, at the World Chemistry Leadership Meeting at the IUPAC Congress and General Assembly, to debate chemistry's role in realizing the UN Sustainable Development Agenda. (see WCLM report below) This strategic summit encouraged young chemists, IUPAC officials, industry leaders, and some of the most highly renowned chemists (including Nobel laureates) to brainstorm how to efficiently contribute towards these goals and how to inspire the next generation of chemists to design a more sustainable future. After more than ten years of involvement in IUPAC in several roles, most lately as a member of the Bureau, I am convinced that IUPAC has

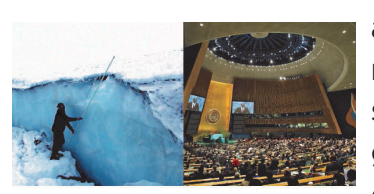
a central role to play in this regard. IUPAC's new mission statement positions the organization as "the global organization that provides objective scientific expertise REVIEW UFTARGEIS FOR
THE SUSTAINABL DEELLPMENT GOALS:
THES SCIENEE PERSPECTIVE

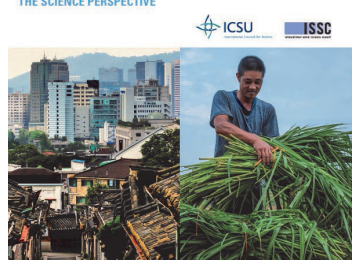
and develops the essential tools for the application and communication of chemical knowledge for the benefit of humankind and the world." In this way IUPAC is already the Sustainability Journey of the European Chemical Industry'. And Professor Javier Garcia Martinez, Department of Inorganic Chemistry, University of Alicante, Spain, emphasized the important role of chemistry and chemists play in sustainable development with his talk: 'The Chemical Element: How Chemistry is Key to Solving our Global Challenges'.

Post GA, the plans are to pair YOs groups working on these proposals with appropriate division mentors facilitate submission to the IUPAC project review process.

The 2015 WCLM project task group includes Laura L. McConnell, Past President, Div VI, Mei-Hung Chiu, Past Chair, CCE, Jan Apotheker, Secretary, CCE, Hemda Garelick, Secretary, Div VI, Bernard West, Chair, COCl, Fabienne Meyers, Assoc. Director, IUPAC, and Natalia Tarasova, IUPAC President.

\section{References}

1. www.un.org/sustainabledevelopment/ sustainable-development-goals/

For more information, see IUPAC project 2015-004-1-020 www.iupac.org/project/2015-004-1-020 


\section{Tackling the Big Challenges of the Future}

making significant contributions towards achieving the Sustainable Development Goals.

1. IUPAC serves as an international and independent platform for chemists to discuss the best technical solutions to important problems such as those related to water, food, energy, and health.

2. IUPAC is the voice of chemists in international forums like UNESCO, ICSU, and Future Earth, and at regional and national chemistry conferences.

3. By providing a common language, verified data, and standardized terminology, IUPAC is already contributing meaningfully to the foundation needed to create technical solutions. The impact of IUPAC's work in these areas is not always recognized for the enabling function it provides.

4. IUPAC is funding very important projects with some seed money. Some examples include the determination of critically important verified data ranging from isotope abundance to solubility constants, financial assistance for scientific conferences in developing countries, and the publication of educational materials, such as the periodic table of the isotopes. Many times, these projects have an incredible valuable, which speaks to the commitment of our volunteers and to the amazing good use IUPAC makes of its limited resources.

5. Both the IUPAC Committee on Chemistry and Education (CCE) and the Committee on Chemistry and Industry $(\mathrm{COCl})$ are uniquely positioned to serve as forums for discussing the best ways to teach and learn chemistry, as well as to bridge the gap between academia and chemical industries. Our success in these areas will determine to a great extent how relevant IUPAC will be in the coming decades.

Too often, IUPAC is unknown, even to chemists. Worse, it can be either idealized, or else vilified by many who see it as bureaucratic, outdated, and political. In August 2015, the Council approved the new IUPAC strategic plan. This plan, whose development was led by our Past President Mark Cesa, provides an excellent roadmap that has been specifically designed to encourage and facilitate projects with multidisciplinary impact, especially those at the interface between the sciences, science and engineering, and science and policy. [10] With our Centenary on the horizon in 2019, the next two biennia are a golden opportunity to position IUPAC as a key contributor to the Global Goals, building on the amazing work that our thousands of volunteers do through the project system, creating a common and universally-accepted language for science, commerce, and law, a huge body of verified data, and an independent and globally respected scientific forum for discussion, work, and planning.

The Sustainable Development Goals can serve us as a inspiration towards our Centenary, as they are worth the effort of a new generation of chemists, who, inspired by the ambition, impact, and urgency of this international call, can truly change the world. What better career path?

\section{References}

1. The UN Sustainable Development Goals: www. un.org/sustainabledevelopment/

2. J. W. Erisman at al., Nature Geoscience 1, 636-639 (2008)

3. Jeffrey Sachs, End of Poverty, Penguin Books (2006)

4. J. Garcia Martinez, E. Serrano Torregrosa, The Chemical Element: Chemistry's Contributions to Our Global Future, Wiley-VCH (2011)

5. J. Garcia Martinez and P. Atkins, Chem. Int. 37(4) 8-14, 2015, http://dx.doi.org/10.1515/ci-2015-0403.

6. J. Garcia Martinez, Science Careers, 20 Mar 2014; www.sciencemag.org/careers/2014/03/ third-way-becoming-academic-entrepreneur

7. 7. Y. Lu, N. Nakicenovic, M. Visbeck, A-S. Stevance, Nature 520, 432-433 (23 April 2015)

8. Review of Targets for the Sustainable Development Goals: The Science Perspective (2015); www.icsu. org/publications/reports-and-reviews/review-of -targets-for-the-sustainable-development-goals -the-science-perspective-2015

9. How can science policy help to deliver the global goals?, The Guardian, 9 Oct 2015; www. theguardian.com/science/political-science/2015 /oct/09/how-can-science-policy-help-to-deliverthe-global-goals

10. M. Cesa, Chem. Int., 38(1) 4-5, 2016; http://dx.doi. org/10.1515/ci-2016-0104

Javier Garcia Martinez <j.garcia@ua.es> is professor at the University of Alicante, Spain where he leads the Molecular Nanotechnology Laboratory and conducts world-class academic research on nanomaterials for energy and environmental applications. He regularly teaches at both undergraduate and graduate levels. Engaged in IUPAC since 2006, he has held several positions, including membership in the Bureau, the Committee on Chemistry Education, the Interdivisional subcommittee on Materials Chemistry, and the Inorganic Chemistry Division. 


\section{DE DE GRUYTER}

\section{YOUR SHORTCUT TO IUPAC STANDARDS}

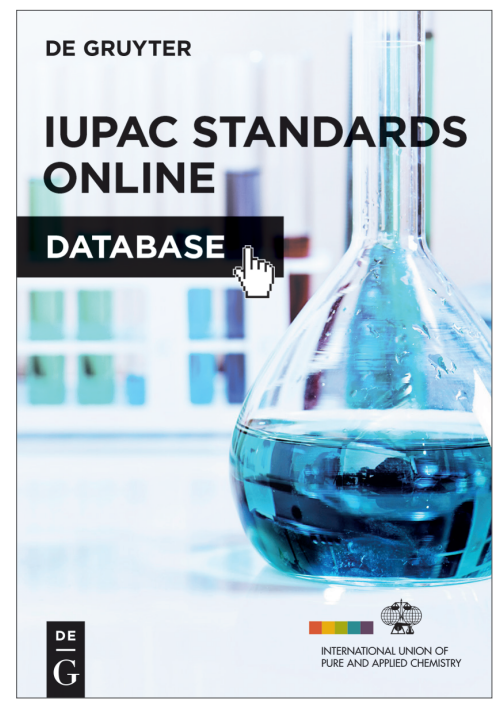

\section{TEST THE NEW IUPAC DATABASE \\ Test the database yourself and activitate your 30 days of free online trial. Your access token: IUPAC-database \\ Discover how to get access: degruyter.com/accesstoken}

This trial does not include any contractual obligations

IUPAC Standards Online is a database built from IUPAC's standards and recommendations, extracted from the journal Pure and Applied Chemistry (PAC). The database will be the only product that provides for the quick and easy search and retrieval of IUPAC's standards and recommendations which until now have remained unsorted within the huge Pure and Applied Chemistry archive.

- Useful: IUPAC's standards and recommendations easily discoverable

- Comprehensive: standard values and procedures; nomenclature, terminology and symbols in chemistry and materials properties of elements, etc.

- Smart: topical structure, advanced search, cross linked entries

- Covering topics in: Analytical Chemistry, Biochemistry, Chemical Safety, Data Management, Education, Environmental Chemistry, Inorganic Chemistry, Materials, Medicinal Chemistry, Nomenclature and Terminology, Nuclear Chemistry, Organic Chemistry, Physical Chemistry, Theoretical \& Computational, Chemistry, Toxicology 